\title{
TRAINING OF SPECIALISTS IN INFORMATION AND MEASUREMENT INSTRUMENTATION IN THE COMPETENCE DISCOURSE
}

\author{
Svetlana Kvesko $^{1}$, Tatyana Shinn $^{2}$ \\ ${ }^{1}$ National Research Tomsk State University, 634050, Tomsk, Russia \\ ${ }^{2}$ Missouri University of Science and Technology, 65401, Rolla, Missouri, USA
}

\begin{abstract}
Refocusing the assessment of the results of educational process from "qualifications" to the concepts of "competence" and "competency" is important in the context for the theoretical and methodological analysis of training in the sphere of information and measurement instrumentation and technologies. The purpose of this paper is to study of the training of today's experts in the field of Information and Measurement Technologies and Instrumentation in the competence discourse. Based on the application of the analysis and interdisciplinary approach methods, the authors concluded the integrative nature of competency-based approach in educational process. The research has revealed the key social competencies and their characteristics.
\end{abstract}

\section{Introduction}

Today's socio-cultural context is experiencing the strongest influence of the human creativity. In the technogenic civilization, the rapid advancement of technology and machinery leads to development of new behavioral styles and changes the entire rhythm of living. The society is evolving into a non-linear informational entity.

The inter-dependencies of a human being, society and nature are enormous which may have both positive and negative impact on the process of resolving of various social issues. This, in turn, has direct implications for the informational processes in the society, and as a result, for the process of education. The quality of general education is closely tied to the level of professionals produced by the system. Presently, we witness the growing significance of the application of informational and measurement instruments and technologies for the development of professionalism, professional confidence and image, and therefore, the approach based on the concepts of competency is gaining influence.

\section{Method}

The shifting focus of the assessment of the education process and of measuring the success of student learning to the concepts of competency dictates the need the for theoretical and

"Corresponding author: svetla_kvesko@mail.ru 
methodological analysis of the professional education programs in the field of informational and measurement instrumentation and technologies. It should be noted, first of all, that the very definition of such approach may have different interpretations.

In our paper, the competency-based approach is to be understood as a cognitive process based on the categories of "competence" and "competency" [1].

The methodological analysis of the problem of professional education in the field of informational and measurement instrumentation and technology assumed the need for a research in order to determine the meaning and the role of competencies in the process of education. The competency-based education is comprised of the methods and procedures related to the development of the educational technology. The meaning of the competencybased approach cannot be understood without the concept of competency as the integral system means of study [2].

The competency approach has a complex hierarchical and multi-level structure with many components and is directly related to the system, structural, functional, problemfocused and genetic approaches to the understanding of the realities and events. Such approach is focused on an individual and his actions. The competency approach relates to the purpose and the outcome of education [3].

\section{Main content}

The competency approach is very important for the professional education in the field of information and measurement equipment and technology, as it focuses the attention on the important issues and offers integral solution to those. Without a doubt, competency is a requirement the society has for the product of education, however, this concept is somewhat removed from a future professional. Being competent is more than learning the classroom material; it is possession of certain skills, competencies, personal characteristics and qualities.

Administering competency-based education requires a clear definition of competencies and development of valid, reliable assessments. Getting industry input is essential to ensuring the identification of the relevant competencies in the field of informational and measurement instrumentation and technology.

The fundamental competencies in the field of informational and measurement technology are those of the humanities, general professional and occupational. These competencies shape the social position of those being educated, their actions and social roles. In the process of education, the competencies form the guidelines for an individual's future professional activity and for navigating the future.

The competencies stimulate each student to master the means and methods of learning and professional practice, understand the process of assessment and application of information and outcomes. Possession of competencies enables an individual to solve problems, coordinate the work of specialists in multiple spheres of applied informational and measurement technologies and scientific knowledge. The role and specifics of competencies may be analyzed from the perspective of the fundamentals of education in the field of information and measurement technology.

We believe it necessary to stress the importance of the competencies of individual values and meaning for the field of informational technology. These competencies are defined by the moral guidelines in the social and informational world. They mean more than just establishing the level of comprehension, but rather an individual's ability to understand the world while realizing his own contribution to the advancement of the innovations and modern technology. The break-through technologies are highly valued in today's world, but their development is only possible in the context of the value- and meaning-based competencies. 
The values- and meaning-based competencies enable individual self-actualization and guide in the choice of life purpose, attitudes and decision-making. These attitudes determine the trajectories of educational and spiritual pursuits. The value-based competencies play a significant role in the formulation of an expert assessment of realities and events, as well as the outcomes of the educational, scholarly, and practical endeavors.

The internal component of the competency (personal competency) is dependent on the individuality and is rooted naturally in the system of individual perceptions of self and one's role in the social context. Personal competency is explicated from an individual's abilities to understand and reflect upon one's role in the society, and to develop life-long goals based on personal values and motivations. The external component of the competency is defined by the individual relationship with the society and social environment. From the moment of choosing a future profession, and individual receives an orientation that determines his actions toward satisfying his aspirations for professionalism.

There is another group of competencies that is cognitive-based. Those are competencies related to educational and learning pursuits and include establishing goals, reflection and self-reflection, logical thinking and methodology. Mastering these competencies requires the use of computer tools and technologies in the educational process. The cognitive-based competencies aid in the refinement of classical forms of education and development of distance-based educational environment.

The special emphasis is being placed on the informational competencies. In the process of acquiring these competencies, an individual develops skills, abilities and knowledge related to the application of information in learning, professional practice and everyday life situations.

The modern means of information and technology require a significant level of knowledge of computers. In everyday life, in professional environment and in the classroom, an individual is faced with the latest technology and equipment, which quickly become outdated and obsolete thus causing a constant stress of catching-up. This may lead to an emotional and sometimes a professional burn-out [4].

Today's digital instruments and technologies in information enable a quick and efficient search for publications and data, aid in their analysis, and streamline interpersonal communication through the use of email, chat, and videoconferencing.

Communicational competencies should also receive our attention. These competencies center around language skills and means of communication. Communicational competency also means the possession of the informational communication skills, knowledge of search engines, social media, video- and audio-communication. The communicational practice within the Internet community plays an important role in the process of mastering these competencies.

Communicational practices are essential components of the cultural dialogues, intercultural socialization, as well as of the business interactions. To be successful in communication within the Internet community and related interactions, one must possess linguistic competencies, be skilled at self-presentation, be knowledgeable in the informational technologies and their practical applications [5].

The implementation of communicational practice via informational and measurement instruments requires flexibility in a changing environment and ability to compromise. These skills are highly valuable in the multi-ethnic, multi-lingual and multi-confessional social world.

The competencies discourse outlines the informational context of education. The informational context of education is comprised of the programming tools, software and hardware, information technologies. Computer-mediated instruction facilitates an individualized approach to education of each student. Because individuals learn at a different pace and enter the professional education program with different levels of prior 
knowledge and experience, this is a fundamental requirement of competency-based education [6].

The analysis of the state of the informational context of education allows us to formulate several key points of today's education and practice in the field of information and education:

1. Today's informational context of education is comprised of multiple components and includes classroom training resources and programming, tests, surveys, graphic and video tools, databases and search engines.

2. Informational context of education has an integral nature, incorporating the wealth of knowledge in the field of informational and measurement equipment, technologies, science, as well as the reference foundation.

3. The distributive quality of the informational context supports the effectiveness and economic efficiency of the technical tools by optimizing the access to the information.

4. The informational context of education is adaptive which enables a flexible use of informational instruments according to the interests and needs of the society.

In the context of the above key points, the informational and measurement field is being regarded as both a part of a general education environment and an autonomic system designed to form an active social and creative personal position that would incorporate the latest informational tools, instruments and technologies [7]. The informational context of education is based upon the whole spectrum of disciplines and subjects and the interactive support factors that are used in the training process.

The term "informational context of education" emerged with the development of the information technology and instruments. Ever since the computer and information technologies infiltrated the education process and became widely used in training, the methodological and administrative support is being designed and regulated for a wideranging application of the modern technology.

At implementation of projects both technical, and social there is a question of responsibility of scientists as scientific decisions not always guarantee positive social result. Owing to this fact carrying out social and humanitarian examination is actual. The question of responsibility of designers is treated from the point of view of positive practical application both for all society, and for each certain person, for change of public states. Often responsibility is treated as fault for insufficiently optimum result, for result, which negative in development of social states, for the consequences leading to tragedies, disasters.

\section{Conclusion}

The global impact of computers and information technology on education has resulted in significant advancement of the technical and didactical resources. As the informational environment evolves, new effective forms of education emerge (distance learning, the organization of independent work in Moodle system, etc.).

Advantages of the modular principle:

1. The informational context of competency-based education is based on the modular principle. The modular approach creates a separate subject within the discipline of information engineering as a unit independent of other subjects. This approach corresponds with the western model of competency-based education in information technology and engineering fields.

2. The advantage of the above principle for the education is in the simplicity of its application.

3. The most important characteristic of competency-based education is that it measures learning rather than time it takes to complete professional training. 
There are, however, the disadvantages of using the modular principle:

(1) The contradiction between the integral system of knowledge and the assortment of disconnected from each other individual areas of expertise.

(2) The lack of "the big picture", as the large number of modules/units impedes the effective generalization of the material learnt.

(3) The subjectivity related to personalities of the module creators/authors.

Overall, the concept that incorporates the informational and competency-based context while preserving the traditional system of education, offers a significant contribution toward the development of an innovative model of education [8]. The application of information technology and computer measurement instruments in the process of education leads to the advancement of social networking, while the rapid growth of computer and information technologies and their efficiency facilitates development of the distance education. As the society is evolving into the "society of information", the social and information technologies are impacting the educational system. The problem of changing paradigms in the field of information and measurement instrumentation training must be addressed in the context of general modernization of the process of education. The conducted research illustrates that the information technologies are essential instruments of the educational process.

\section{Acknowledgment}

This research is carried out under the scope "Organization and methodic issues of training specialists in Information and Measurement Technologies and Technique. Passes with assistance of a grant of the Russian fund of basic researches №16-07-20218, and the program of improving competitiveness of the TSU (project No. 8.2.31.2015).

\section{References}

[1] M. Mayhew, J. Simonoff, W. Baumol, B. Wiesenfeld, M. Klein, Research in higher education 53, 831 (2012)

[2] A.Yu. Chmykhalo, R.B. Kvesko, T. Shinn. Global Science and Innovation 6, 85 (2015)

[3] O. Bleikher, S. Kvesko, Applied Mechanics and Materials 770, 651 (2015) doi: 10.4028/www.scientific.net/AMM.770.651

[4] N.V. Sosnin, Competence-based approach in innovative engineering education (Izdvo RO IPK i PRO, Krasnoyarsk, 2006)

[5] J. Cosling \& H. Mintzberg. HBR 81, 54 (2003)

[6] M. Lehmann, P. Christensen, X. Du, M. Thrane. EJEE. 33, 283 (2008)

[7] S. Gorbachev, M. Syryamkin, V. Syryamkin \& E. Vaganova, XVth International Conference Linguistic and Cultural Studies: Traditions and Innovations (LKTI 2015) 206, 382 (2015)

[8] V.I. Syryamkin , E.G. Syryamkina, Procedia - Social and Behavioral Sciences 166, $471(2015)$ 